\title{
Evaluation of a new hybrid technique for closure of muscular ventricular septal defects in a long-term setting
}

\author{
Rainer Kozlik-Feldmann, MD, ${ }^{a} *$ Nora Lang, MD, ${ }^{\mathrm{a} *}$ Anja Lehner, MS, ${ }^{\mathrm{a}}$ Matthias Sigler MD, \\ Christoph Schmitz, MD, ${ }^{\mathrm{b}}$ Ralf Sodian, MD, ${ }^{\mathrm{b}}$ Franz Freudenthal, MD, ${ }^{\mathrm{d}}$ Robert Dalla-Pozza, MD, ${ }^{\mathrm{a}}$ \\ Nicolay V. Vasilyev, MD, ${ }^{\mathrm{e}}$ Pedro J. del Nido, MD, PhD, ${ }^{\mathrm{e}}$ and Heinrich Netz, $\mathrm{MD}^{\mathrm{a}}$
}

Objective: Therapy for muscular ventricular septal defects beyond the moderator band, especially in neonates and infants, has always been challenging for both surgeons and cardiologists. Recently, we established a patch closure hybrid therapy for muscular ventricular septal defects. In this study, we evaluated it in a long-term porcine model.

Methods: Thirteen minipigs underwent anterolateral thoracotomy to expose the left ventricle. Muscular ventricular septal defects were created under 2- and 3-dimensional echocardiographic guidance with a 7.5-mm sharp punch instrument. Closure of the defects was undertaken with our new patch system in hybrid technique. Animals were observed for 3 months. Echocardiographic evaluation and pathologic examination, including immunohistochemical staining, were undertaken.

Results: Defects were successfully created in 12 pigs and closed in 10 pigs. Seven survived for 3 months. Residual shunting was noticed in 1 animal. Neither left ventricular dysfunction nor relevant damage to the valves could be detected. Pathologic examination showed complete endothelialization of the patch and the nitinol anchors without protruding parts of the system. Cellular organization was proceeding. Immunohistochemical staining demonstrated endothelial cells on the surface of the patch and fibromuscular cells around the patch.

Conclusion: Our hybrid therapy was efficacious in closing muscular ventricular septal defects without impairment of cardiac function. The patch system and nitinol anchors demonstrated good integration into the septum. Further development of the system for human application is already being undertaken.

Earn CME credits at

http://cme.ctsnetjournals.org
Hybrid therapy, which combines surgical and interventional techniques, is a new, innovative approach for the treatment of complex congenital malformations. Although each of these techniques alone is limited, collaboration between surgeons and cardiologists may enable complex procedures that could not be attempted independently. Early experience has shown that hybrid therapy may reduce operative times, decrease proce-

\footnotetext{
From the Departments of Pediatric Cardiology, ${ }^{a}$ and Cardiac Surgery, ${ }^{\mathrm{b}}$ Hospital Campus Grosshadern, University of Munich Hospital-Großhadern, Munich, Germany; the Department of Pediatric Cardiology and Intensive Care, Georg August University, Göttingen, Germany ${ }^{c}$; the Department of Pediatric Cardiology, Kardiozentrum, La Paz, Bolivia ${ }^{\text {; }}$, and the Department of Cardiac Surgery, Children's Hospital Boston and Harvard Medical School, Boston, Mass. ${ }^{\mathrm{e}}$

Supported by Elterninitiative Großhadern eV and Heart for Heart Foundation, Munich, Germany. Philips Healthcare Nederland BV, Eindhoven, The Netherlands, provided the 3-dimensional echocardiography.

* R.K.-F. and N.L. contributed equally to this article.

Received for publication Oct 8, 2008; revisions received Jan 11, 2009; accepted for publication Feb 9, 2009; available ahead of print April 30, 2009.

Address for reprints: Rainer Kozlik-Feldmann, MD, Department of Pediatric Cardiology, Hospital Campus Grosshadern, University of Munich Hospital-Großhadern, Marchioninistraße 15, D-81377 Munich, Germany (E-mail: kozlik-f@lrz. uni-muenchen.de).

J Thorac Cardiovasc Surg 2009;138:365-73

$0022-5223 / \$ 36.00$

Copyright (C) 2009 by The American Association for Thoracic Surgery

doi:10.1016/j.jtcvs.2009.02.014
}

dural complexity and operative trauma, avoid the use of cardiopulmonary bypass (CPB), and improve procedural outcomes. ${ }^{1-3}$

Therapy for muscular ventricular septal defects (mVSDs) beyond the moderator band is still challenging. Both surgical and interventional strategies for mVSD closure are still problematic. Reoperation rates as great as $10 \%$ have been reported after surgery. ${ }^{4-6}$ Further, surgery requires the use of $\mathrm{CPB}$, which may be associated with neurologic complications ${ }^{7,8}$ or the development of a systemic inflammatory response syndrome. ${ }^{9}$ Interventions can be limited by poor vascular access, low patient weight, and rhythm disturbances. ${ }^{1,10,11}$

Hybrid therapy seems to be a new option for treatment of mVSDs. Several authors have reported on off-pump closure of mVSDs with an Amplatzer device (AGA Medical Corp, Plymouth, Minn) through a perventricular approach. ${ }^{1,12,13}$ They have reported advantages relative to open repair, including avoidance of transection of the moderator band or other right ventricular muscle bundles without the limitations of vascular access or patient weight. ${ }^{12}$ They have also, however, reported valve injuries, device embolization into the aorta, rhythm disturbances, and device migration. ${ }^{1,13}$

Recently, we published a hybrid technique for patch closure of mVSDs from the left ventricle (LV). ${ }^{14}$ Efforts to establish a monodisk system for closure of cardiac septal defects have been made before. ${ }^{15}$ In principle, a patch delivery device consisting of a polyester patch and a nitinol frame was passed through the carotid artery into the LV. Thereafter, the patch was fixed with 8 to 10 nitinol anchors through LV puncture with a specially designed stapler system. 


$$
\begin{aligned}
& \text { Abbreviations and Acronyms } \\
& \begin{aligned}
\mathrm{CPB} & =\text { cardiopulmonary bypass } \\
\mathrm{FS} & =\text { fractional shortening } \\
\mathrm{LV} & =\text { left ventricle } \\
\mathrm{mVSD} & =\text { muscular ventricular septal defect } \\
\mathrm{PAP} & =\text { pulmonary arterial pressure } \\
\mathrm{PCWP} & =\text { pulmonary capillary wedge pressure } \\
\mathrm{SEM} & =\text { scanning electron microscopy }
\end{aligned}
\end{aligned}
$$

Closure was done under echocardiographic and fluoroscopic control. Finally, the nitinol frame was detached from the patch. In short-term porcine model, we demonstrated the general feasibility of this technique. ${ }^{16}$ In this study, we report our results on the evaluation of this technique in a long-term porcine model in which residual shunting, development of LV dysfunction, and integration of the patch into the septum were especially addressed.

\section{MATERIALS AND METHODS}

\section{Animals}

Thirteen Göttingen minipigs (Ellegaard Göttingen Minipigs $\mathrm{A} / \mathrm{S}<$ Dalmose, Denmark) of either sex $(20-30 \mathrm{~kg})$ were used in an experimental protocol that was approved by the local Governmental Commission on the Care and Use of Animals $(\mathrm{n}=13)$. They received care in compliance with the Guide for the Care and Use of Laboratory Animals (www.nap.edu/ catalog/5140.html). Experiments were performed in the laboratory of surgical research, Walter Brendel Center for Experimental Medicine, at the Ludwig Maximilians University of Munich.

\section{Anesthesia and Surgical Preparation}

Anesthesia and surgical preparation were performed as described previously. ${ }^{14,16}$ Briefly, the right-sided carotid artery and jugular vein were surgically exposed, and the artery was cannulated with a $9 \mathrm{~F}$ introducer sheath and the vein with an $11 \mathrm{~F}$ introducer sheath. Arterial pressure and central venous pressure were measured continuously. At 1-month follow-up the left-sided external carotid artery and the jugular vein, and at 3 month followup the femoral vein and artery were used for arterial and venous access. Afterward, a left thoracotomy in the fifth or sixth intercostal space was performed. After opening of the pericardium the heart was exposed. The entire procedure was carried out without CPB. Two Teflon-armed, purse-string sutures were applied on the LV wall for instrument insertion.

\section{Creation of mVSDs}

Creation of mVSDs was achieved under 2- and 3-dimensional echocardiographic guidance, as described previously. ${ }^{16}$ For 2-dimensional echocardiography (Sonos 5500; Philips Healthcare Nederland BV, Eindhoven, The Netherlands), a $5-\mathrm{MHz}$ transesophageal echocardiographic probe was placed behind the heart through an additional incision in the sixth intercostal space. Epicardial real-time 3-dimensional echocardiography was performed with the X7-2 matrix transducer of the iE33 Ultrasound System (Philips Healthcare). Successful mVSD creation was confirmed by echocardiography and by oximetric measurement of the shunt volume by the Fick method.

\section{Closure of mVSDs and Follow-up}

The patch delivery device and the custom-designed stapler for fixation have been described in earlier publications. ${ }^{14,17,18}$ During the study period, we modified the stapler and introduced a 2-step releasing system for better prevention of anchor embolism. A pause in the fixation process occurs shortly before the forceps inside the stapler releases the nitinol anchor, so that the operator can ensure that the nitinol anchor is still in right position and is well fixed in the tissue. The nitinol anchor is then released in a second step. Closure of the mVSDs was undertaken as described previously. ${ }^{14}$ Briefly, the patch delivery device was inserted into a custom-designed, 30-cm long 7F sheath. It was forwarded over a $6 \mathrm{~F}$ pigtail catheter through the $9 \mathrm{~F}$ introducer sheath across the carotid artery into the LV. The patch was deployed and positioned over the defect under fluoroscopic and echocardiographic guidance. The custom-designed stapler was introduced through a 7F sheath inside the lateral LV wall. Subsequently, the patch was fixed with 8 to 10 nitinol minianchors under epicardial 3- and 2-dimensional echocardiographic and fluoroscopic guidance. After fixation was secured, the nitinol frame was detached from the polyester patch by releasing the sutures (Figure 1) and was drawn back into the long $7 \mathrm{~F}$ sheath. Figure 1 shows the essentials of our therapy and an ex vivo demonstration of the main principle of our technique.

Follow-ups were undertaken after 1 and 3 months. All animals received aspirin for 3 months.

\section{Hemodynamic Measurements and Echocardiography}

Heart rate, arterial pressure, and central venous pressure were measured and recorded periodically. The following hemodynamic parameters were measured as baseline before thoracotomy: central venous pressure, pulmonary arterial pressure (PAP), and pulmonary capillary wedge pressure (PCWP). Initial echocardiography was performed to exclude heart defects and to determine the basal fractional shortening (FS). After shunt creation and closure of the defects, the same hemodynamic parameters were measured. Blood samples were taken to measure shunt volume. Echocardiography was used to assess the diameter of the mVSD.

After defect closure, echocardiography was performed to detect potential residual shunts and valve insufficiencies. Additionally, residual shunt volume was determined by measuring required hemodynamic parameters.

At follow-up, arterial pressure, central venous pressure, PAP, and PCWP were measured, and detailed echocardiography was done to evaluate cardiac function, especially to investigate valve function and insufficiencies. Measurements of FS and stress echocardiography with dobutamine (FreseniusKabi, Bad Homburg, Germany) were performed to quantify cardiac function. Residual shunts were estimated from echocardiographic and hemodynamic measurements.

\section{Pathologic Studies}

Tissue preparation. After the 3-month follow-up, animals were killed by intracardiac injection of $40 \mathrm{mEq}$ potassium chloride (Braun, Melsungen, Germany). After explantation of the heart, macroscopic evaluation and documentation were performed. The tissue block containing the patch and the anchors was dissected with a minimum of surrounding tissue.

After brief flushing with saline solution, specimens were fixed in formalin (buffered 4\%) and prepared for histologic and immunohistochemical examination. For scanning electron microscopy (SEM), part of the specimen was placed in glutaraldehyde $(2.5 \%)$.

Embedding, sectioning, and histologic examination. After fixation, most of the tissue block was embedded in methyl methacrylate resin (Technovit 9100; Kulzer \& Co, Wehrheim, Germany). ${ }^{19}$ After hardening, the resin blocks were subsequently sectioned in slices of $0.8 \mathrm{~mm}$ with a diamond band saw (300 CP; Exakt GmbH, Norderstedt, Germany). The slices were ground down to 5 to $30 \mu \mathrm{m}$ with a horizontal rotating grinder and polisher (400 CS; Exakt). Staining of resin-embedded specimens was performed with Richardson blue.

Immunohistochemical staining. Preparation of the sections for immunohistochemical staining was performed with deplastification of the tissue and mounting on glass slides. ${ }^{20}$ Binding of primary antibodies was detected with horseradish peroxidase-conjugated secondary antibodies. 

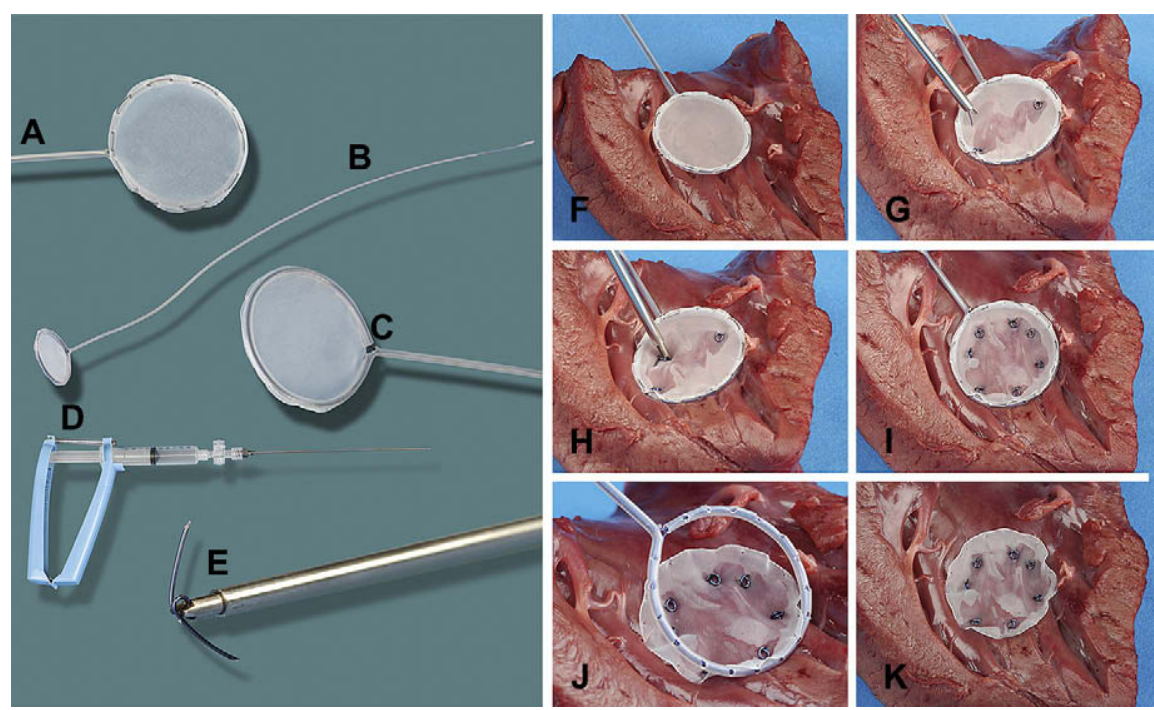

FIGURE 1. Principle of hybrid therapy. A through C, Polyester patch and delivery system; D, stapler; E, stapler tip with nitinol anchor. F, Patch delivery device is put on piece of muscular septum. G and H, Fixation of nitinol minianchor on muscular septum with custom-designed stapler. I, Fixation of patch with 7 nitinol minianchors. J, After release of sutures, nitinol frame detaches from patch. K, Patch remains in muscular septum with nitinol minianchors.

The sections were counterstained with hemalaun. We used antibodies against von Willebrand factor for identification of endothelial cells. Antibodies against smooth muscle actin and vimentin were used for analysis of cellular components of the newly formed tissue within the closed septal defect and around the device.

Scanning electron microscopy. Part of the specimen was prepared for SEM and placed in glutaraldehyde $(2.5 \%)$ for fixation. Images were obtained after critical-point drying and gold coating of the specimen. Scanning electron microscope (Zeiss DSM 940; Carl Zeiss NTS GmbH, Oberkochen, Germany) was used for examination.

\section{Statistical Analysis}

Values are presented as mean \pm SD. For comparison of different groups, the paired $t$ test was used.

\section{RESULTS}

\section{Creation and Closure of mVSDs}

Creation of mVSDs under echocardiographic guidance was successful in 12 of 13 animals. The mean size of the created mVSDs, as determined by 2-dimensional echocardiography, was $5.0 \pm 0.8 \mathrm{~mm}$. Shunt volumes ranged from $13 \%$ to $54 \%$ (mean $20.1 \%$ ). The defects were located in the apical $(\mathrm{n}=3)$, midmuscular $(\mathrm{n}=6)$, anterior $(\mathrm{n}=2)$, and inferior $(\mathrm{n}=1)$ septum.

Successful closure of the defects was achieved in 10 of 12 animals (Table 1). Animal 2 had to be killed at the end of the experiment after failure of patch implantation; the patch was located inside the mVSD and therefore did not close it. Furthermore, the papillary muscles of the tricuspid valve were injured by 2 anchors. Animal 10 died of bleeding at the LV. Macropathologic examination showed correct placement of the patch.

\section{Follow-up}

Long-term follow-up was done for 10 animals (Table 1). Seven of 10 animals survived for 3 months. Animal 4 died of lung edema after successful implantation of the patch. The death of animal 9 was considered to be related to our technique. In this case, macropathologic examination revealed that 2 anchors had captured one septal attachment of the tricuspid valve. The patch itself was placed properly. Postprocedural echocardiography showed no impairment of the tricuspid valve. Animal 12 died of a pneumothorax on postoperative day 14. Two animals had postprocedural pneumonia, which was successfully treated with antibiotics.

In animal 3, small residual shunting was seen on echocardiography (Table 1). The animal experiment was not terminated throughout the observation period. Pathologic examination revealed a small dehiscence at the border of the patch.

No clinical evidence of thromboembolic events was found in any of the animals. We found that 2 anchors had embolized into the lung in one animal; this was confirmed with radiographic evaluation at 1-month follow-up. Clinical symptoms caused by embolization were not seen.

\section{Hemodynamics}

Pigs were in hemodynamically stable condition at all time points and received no catecholamines during creation and closure of mVSDs. There was a statistically significant increase in PAP after creation of the mVSD (from $17.7 \pm$ 4.3 to $27.7 \pm 2.9 \mathrm{~mm} \mathrm{Hg}, P<.05$ ), which decreased continuously after closure. A slight elevation in PAP remained after 3 months. PCWP also increased after creation of the defects (from $10.3 \pm 4.2$ to $15.8 \pm 4.8 \mathrm{~mm} \mathrm{Hg}, P<.05$ ), but PCWP decreased to baseline values during follow-up.

\section{Echocardiography}

Relevant echocardiographic data collected during mVSD closure and at follow-up are summarized in Table 1 . 
TABLE 1. Individual courses of ventricular septal defect creation and repair

\begin{tabular}{|c|c|c|c|c|c|c|}
\hline \multirow[b]{2}{*}{ Animal } & \multirow{2}{*}{$\begin{array}{l}\text { VSD location } \\
\text { and size }\end{array}$} & \multirow{2}{*}{$\begin{array}{c}\text { Patch } \\
\text { implantation }\end{array}$} & \multirow{2}{*}{$\begin{array}{c}\text { Reason for } \\
\text { premature death }\end{array}$} & \multicolumn{3}{|c|}{ Echocardiography } \\
\hline & & & & Preoperative & Follow-up, 1 mo & Follow-up, 3 mo \\
\hline 1 & Midmuscular, $4.6 \mathrm{~mm}$ & $*$ & $\dagger$ & $\mathrm{TI}^{\circ} \mathrm{I}$ & $\mathrm{TI}^{\circ} \mathrm{I}-{ }^{\circ} \mathrm{II} ; \mathrm{AI}{ }^{\circ} \mathrm{I} ; \S$ & $\mathrm{TI}^{\circ} \mathrm{II} ; \mathrm{AI}{ }^{\circ} \mathrm{I} ; \S$ \\
\hline 2 & Inlet muscular, $3.2 \mathrm{~mm}$ & $\begin{array}{l}\text { Failure of } \\
\text { implantation } \\
\text { technique }\end{array}$ & $\begin{array}{l}\text { Papillary muscle } \\
\text { hurt by } 2 \text { nitinol } \\
\text { anchors, patch } \\
\text { located in VSD and } \\
\text { in right ventricle }\end{array}$ & $\ddagger$ & - & - \\
\hline 3 & $\begin{array}{l}\text { Anterior muscular, } \\
5.8 \mathrm{~mm}\end{array}$ & $*$ & $\dagger$ & $\ddagger$ & $\begin{array}{l}\mathrm{TI}{ }^{\circ} \mathrm{II} ; \mathrm{MI}{ }^{\circ} \mathrm{I} \text {; trivial } \\
\text { residual shunt }\end{array}$ & $\begin{array}{l}\mathrm{TI}^{\circ} \text { II; trivial } \\
\text { residual shunt }\end{array}$ \\
\hline 4 & Midmuscular, $4.8 \mathrm{~mm}$ & $*$ & $\begin{array}{l}\text { Lung edema } 6 \mathrm{~h} \\
\text { postoperative }\end{array}$ & $\ddagger$ & - & - \\
\hline 5 & Apical, $5.4 \mathrm{~mm}$ & $\begin{array}{l}\text { *; embolization } \\
\text { of } 2 \text { nitinol } \\
\text { anchors into lung }\end{array}$ & $\dagger$ & $\ddagger$ & $\mathrm{TI}^{\circ} \mathrm{I} ; \mathrm{MI}^{\circ} \mathrm{I} ; \S$ & $\mathrm{TI}^{\circ} \mathrm{I} ; \S$ \\
\hline 6 & Apical, $5.4 \mathrm{~mm}$ & $*$ & $\dagger$ & $\begin{array}{l}\text { Bicuspid } \\
\text { aortic valve }\end{array}$ & $\mathrm{AI}^{\circ} \mathrm{I} ; \mathrm{TI}{ }^{\circ} \mathrm{I} ; \mathrm{MI}{ }^{\circ} \mathrm{I} ; \S$ & $\mathrm{PI}{ }^{\circ} \mathrm{III}$ \\
\hline 7 & Apical, $5.0 \mathrm{~mm}$ & $*$ & $\dagger$ & $\mathrm{AI}^{\circ} \mathrm{I}$ & $\mathrm{TI}^{\circ} \mathrm{I} ; \mathrm{MI}^{\circ} \mathrm{I} ; \mathrm{AI}^{\circ} \mathrm{I} ; \mathrm{PI}^{\circ} \mathrm{I} ; \S$ & $\mathrm{TI}^{\circ} \mathrm{I}$ \\
\hline 8 & Midmuscular, $5.8 \mathrm{~mm}$ & $*$ & $\dagger$ & $\ddagger$ & $\mathrm{TI}{ }^{\circ} \mathrm{I} ; \S$ & $\mathrm{TI}^{\circ} \mathrm{I} ; \mathrm{PI}^{\circ} \mathrm{I}$ \\
\hline 9 & $\begin{array}{l}\text { Anterior muscular, } \\
4.7 \mathrm{~mm}\end{array}$ & $\begin{array}{l}\text { Failure of } \\
\text { implantation } \\
\text { technique }\end{array}$ & $\begin{array}{l}\text { Destruction of tricuspid } \\
\text { valve; death } 3 \text { days } \\
\text { postoperative }\end{array}$ & $\begin{array}{l}\text { Atrial septal } \\
\text { defect 3-4 mm }\end{array}$ & - & - \\
\hline 10 & Midmuscular, $4.2 \mathrm{~mm}$ & $*$ & $\begin{array}{l}\text { Bleeding at left } \\
\text { ventricle as } \\
\text { consequence } \\
\text { of torn purse-strings }\end{array}$ & $\ddagger$ & - & - \\
\hline 11 & Midmuscular, $5.8 \mathrm{~mm}$ & $*$ & $\dagger$ & $\ddagger$ & $\mathrm{AI}^{\circ} \mathrm{I} ; \mathrm{TI}^{\circ} \mathrm{I} ; \$$ & $\mathrm{MI}^{\circ} \mathrm{I} ; \mathrm{TI}^{\circ} \mathrm{I} ; \mathrm{AI}^{\circ} \mathrm{I}$ \\
\hline 12 & Midmuscular, $5.3 \mathrm{~mm}$ & $*$ & $\begin{array}{l}\text { Pneumothorax } 14 \mathrm{~d} \\
\text { postoperative }\end{array}$ & $\ddagger$ & - & - \\
\hline
\end{tabular}

$\overline{V S D}$, Ventricular septal defect; $T I$, tricuspid insufficiency; ${ }^{\circ} I$, 1 st degree; ${ }^{\circ} I I$, 2nd degree; $M I$, mitral insufficiency; $A I$, aortic insufficiency; $P I$, pulmonic insufficiency; ${ }^{\circ} I I I$, 3rd degree. *Successful implantation. †No premature death. †No pathology. §No residual shunt.

Although most animals had mild insufficiencies of the tricuspid, mitral, and aortic valves, these insufficiencies declined during the follow-up period. Furthermore, we measured FS to quantify cardiac function during our experiments. Baseline FS value was $40.8 \% \pm 5.0 \%$. FS values after 1 and 3 months were not reduced, indicating that cardiac function was not impaired $(42.8 \% \pm 4.1 \%$ and $41.9 \% \pm 6.5 \%)$. In addition, FS values $(50.0 \% \pm 9.2 \%)$ with dobutamine after 3 months indicated good cardiac function as well.

\section{Pathologic Results}

Animal 13 was killed perioperatively. Macroscopic and microscopic evaluation of this heart 3 hours after creation of an $\mathrm{mVSD}$ revealed a substantial defect, with fibrin coverage of the defect edges and significant hemorrhagic infiltration of the surrounding tissue (Figures 2, $A$ and $B$, and 3, $A$ and $B$ ).

Animal 9 died 3 days after implantation. Correct placement of the patch and its adequate fixation could be seen on explantation; however, the tricuspid valve was infringed with one anchor. In addition, macropathologic examination showed a thin layer of reddish material on the surface of the patch (Figure 2, C). Histopathologic analysis revealed a typical pattern of fibrin condensation, with inclusion of blood cells mainly around the patch (Figure 3, $C$ and $D$ ).

Animal 10 died 14 days after implantation. Explantation showed irregular coverage of the patch with a shiny, glistening, thin surface layer (Figure 2, D). Microscopic evaluation revealed partial neoendothelialization of the patch and the anchors. In addition, initial fibromuscular cellular ingrowth integrated with thrombotic material could also be detected within the defect (Figure 3, $E$ and $F$ ).

Seven animals survived through the 3-month follow-up period. Gross pathologic examination of these hearts revealed correct placement of the patch in 6 of 7 explanted hearts. In 1 heart, a slight and insignificant dislodgment of the patch was detected.

All patches were completely covered by a glistening, smooth, thin layer of neoendothelium with a thickness as great as $1.6 \mathrm{~mm}$. Continuity between the neoendothelium over the patch and the surrounding septal wall was observed, and anchors were completely overgrown by a transparent, superficial tissue layer (Figure 2, $E$ and $F$ ). Histopathologic 

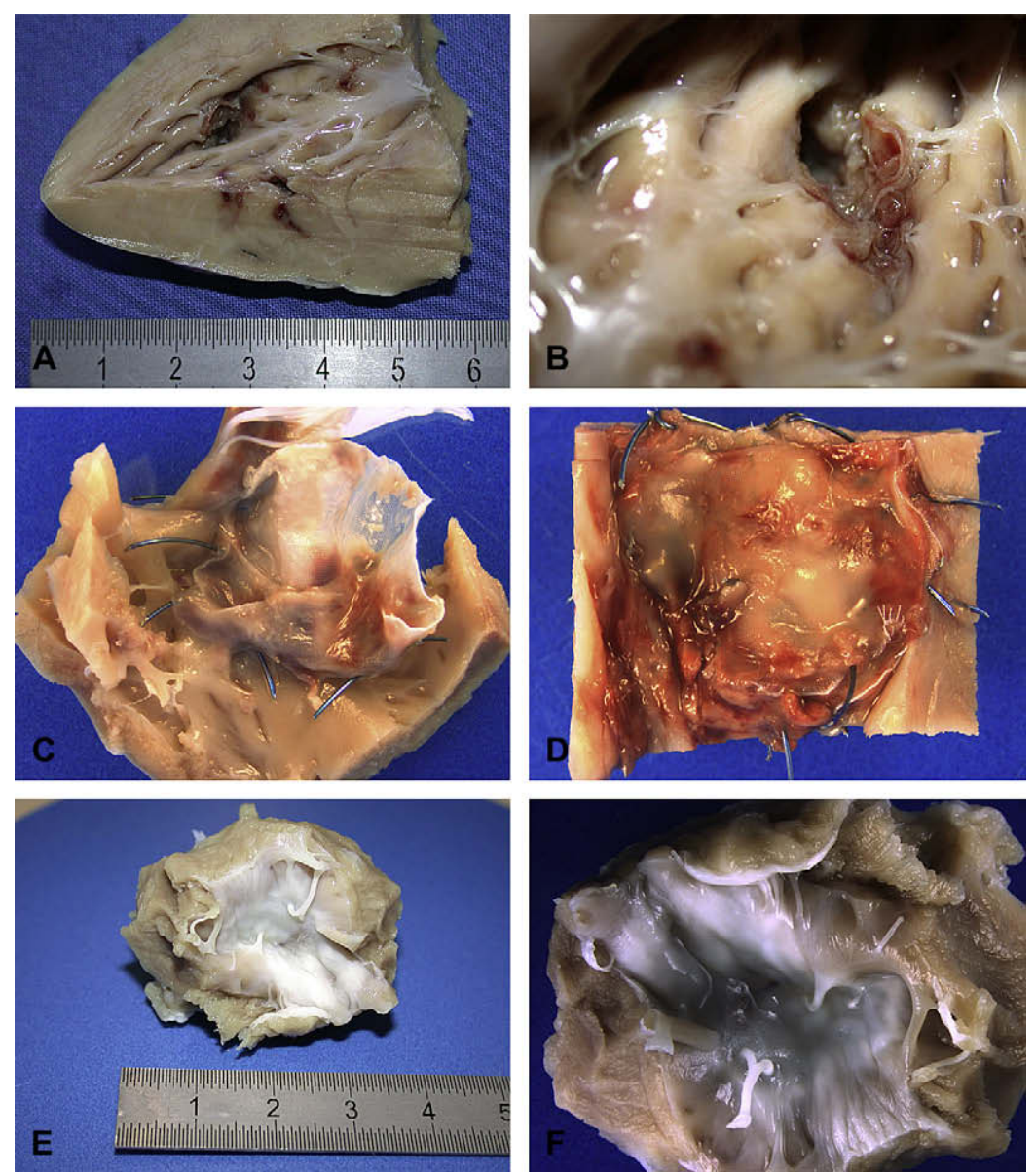

FIGURE 2. Macroscopic evaluation. A and B, Explanted heart after creation of mVSD demonstrates substantial defect created with surrounding bleeding. A, Overview; B, corresponding enlargement. C, Piece of septum from explanted heart 3 days after patch implantation. Thin layer of fibrin on surface of patch and anchors is detectable. D, Patch and anchors 14 days after implantation. Irregular coverage of patch and anchors with shiny, glistening, thin surface layer. E and F, Piece of septum from explanted heart after 3 months. Patch and anchors are completely overgrown by shiny, glistening surface layer. E, Overview; F, corresponding enlargement.

investigations showed ongoing cellular organization of the surrounding septum, with only a few residual areas of unorganized thrombotic tissue. Connective tissue containing fibromuscular cells was predominant. In addition, vascularization was beginning in the newly formed tissue (Figure 3, $G$ and $H$ ).

Immunohistochemical methods were used to characterize different cellular components and showed antigen characteristics of fibromuscular cells (positive staining for smooth muscle actin and vimentin; Figure 4, $B$ and $C$ ). Superficial cells to stained positively for von Willebrand factor (Figure 4, A), which marked them as endothelial cells. Finally, SEM showed complete neoendothelial coverage of the patch and the anchors (Figure 5).

\section{Inflammatory Reactions}

A mild to moderate inflammatory reaction was visible in all specimens. In the heart explanted 3 days postoperatively, copious lymphocytes and a few granulocytes were detectable. Typical multinucleated foreign-body giant cells as well as lymphocytes could be noticed adjacent to the textile membrane of the implant after 14 days and after 3 months (Figure 3,I). No superficial thrombus formation was found in the specimens.

\section{DISCUSSION}

In this study, we demonstrated that with this hybrid technique we were able to close mVSD sufficiently without residual shunting or development of LV dysfunction in a long-term porcine model. Both patch and anchors were overgrown by endothelium and fibromuscular cells, with continuity to the surrounding septal wall. Adequate integration of the patch and the anchors into the muscular septum thus could be determined.

In general, hybrid therapy appears to be a reasonable approach for treatment of mVSDs. ${ }^{1}$ Surgical and 

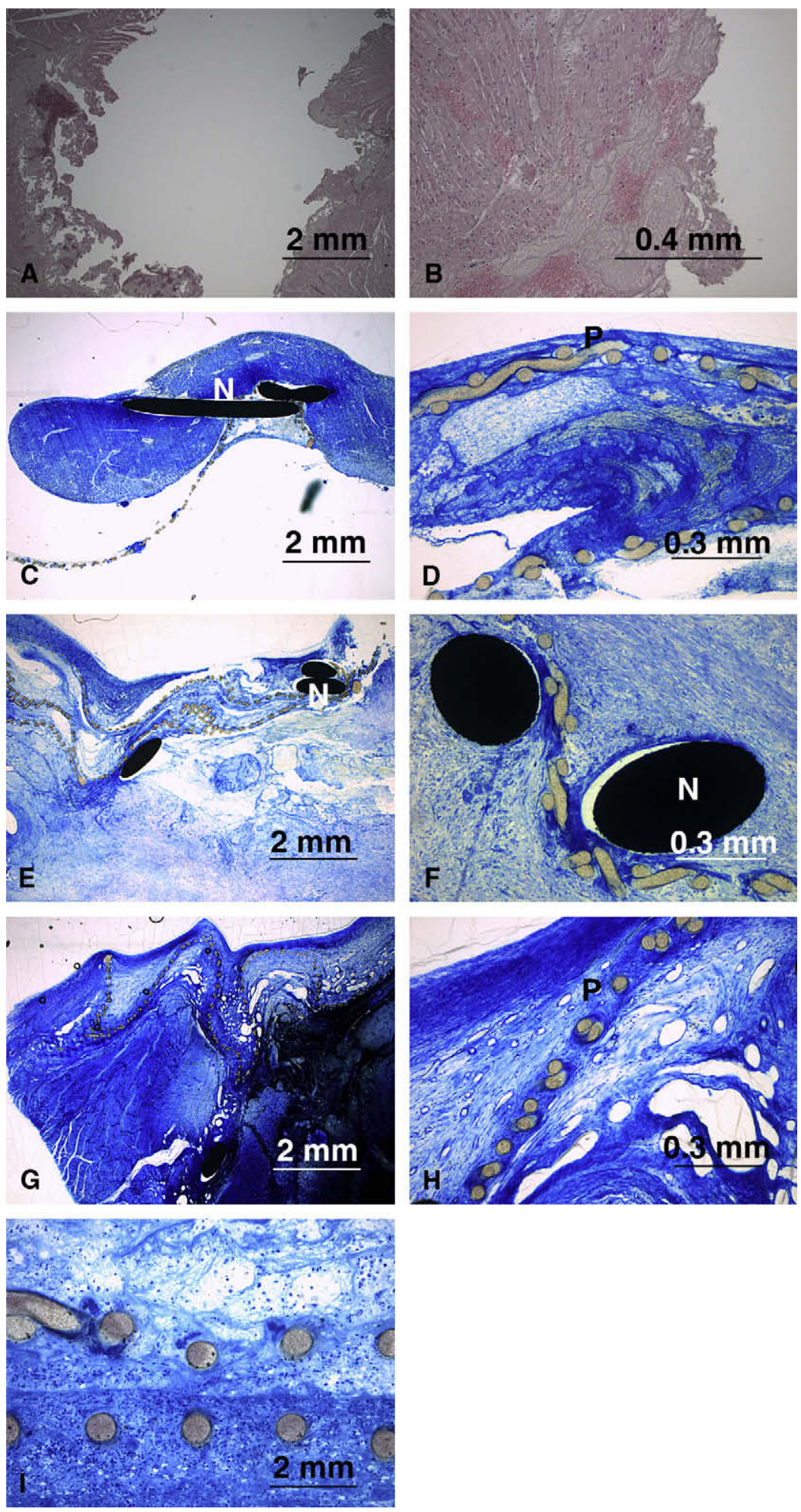

FIGURE 3. Microscopic evaluation. A and B Microscopic evaluation of heart 3 hours after creation of mVSD. A, Creation of substantial defect, with fibrin coverage of defect edges; B, significant hemorrhagic infiltration of myocardial tissue. C and D, Histopathologic analysis of patch and surrounding myocardial tissue 3 days after implantation. Fibrin condensation with inclusion of blood cells mainly around polyester patch $(P)$ can be detected. C, Overview; D, corresponding enlargement. E, Overview of patch 14 days after implantation. Partial neoendothelialization of patch and nitinol anchors $(N)$ is visible. F, Beginning ingrowth of fibromuscular cells around patch and anchors. G and H, Histopathologic investigation of patch and anchors after 3 months. G, Complete neoendothelial coverage of patch and anchors with proceeding cellular organization of septum; $\mathrm{H}$, enlargement showing fibromuscular cells and beginning of vascularization. I, Typical multinucleated foreign-body giant cells in explant 3 months after implantation. 

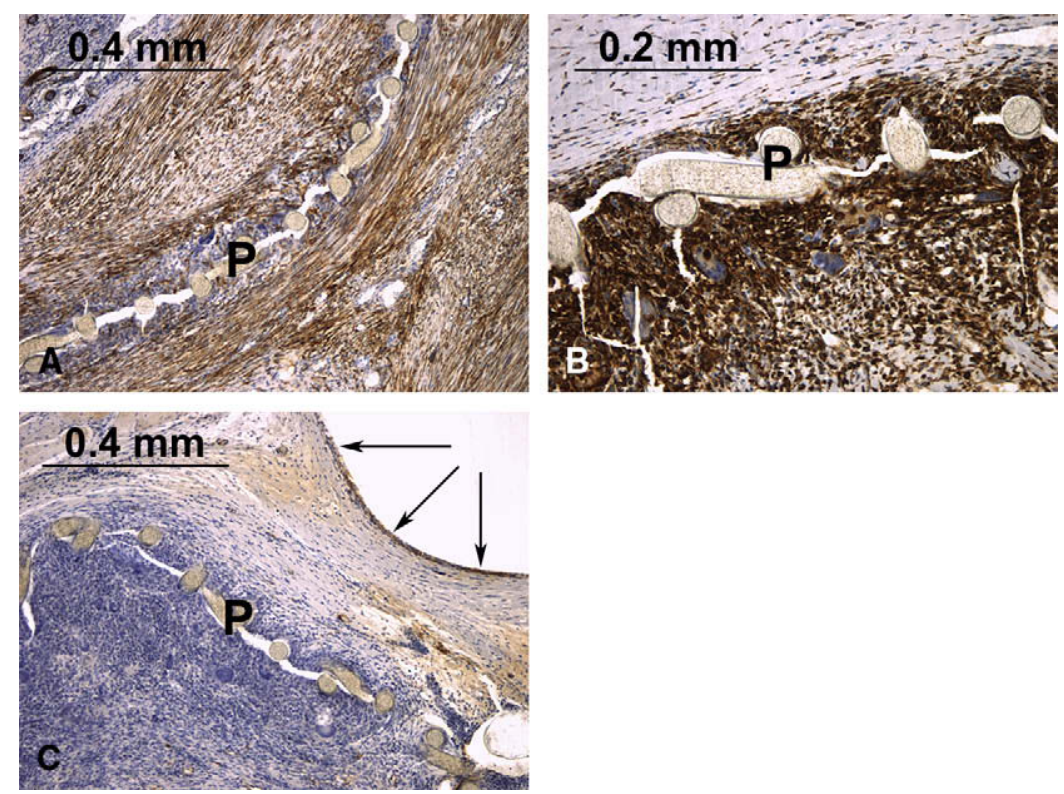

FIGURE 4. Characteristic immunohistochemical staining after 3 months. Staining with antibodies against smooth muscle actin (A) and vimentin (B) demonstrated formation of fibromuscular cells (brown color) mainly around patch material $(P)$; von Willebrand factor staining $(\mathrm{C}$, arrows) confirmed confluent monolayer of cells on surface of patch to be endothelium.

interventional therapies for mVSDs have different disadvantages. Right-sided approaches may not allow correct visualization of the defect, because it is often hidden by muscular trabeculations. ${ }^{21}$ Left ventriculotomy may expose the defect more easily on the smooth surface of the muscular septum, but it is associated with such adverse side effects as LV dysfunction, arrhythmias, and apical aneurysms. ${ }^{6}$ Interventional strategies may be limited by low patient weight or poor vascular access. In small infants, the use of large sheaths may cause rhythm disturbances, hemodynamic compromise, or damage to the atrioventricular valve. ${ }^{1,11,12}$

Recently, there have been several reports of new hybrid therapies for closure of mVSDs and perventricular closure of mVSDs with an Amplatzer device. ${ }^{12,13,22}$ Advantages of these approaches are the avoidance of transection of the moderator band or other right ventricular muscle bundles, avoidance of CPB, and lack of limitation by vascular access or patient weight. Nevertheless, these hybrid therapies still have disadvantages, such as device embolization or migration and development of atrioventricular blocks. ${ }^{12,13,22}$

We therefore developed a new hybrid therapy for mVSD patch closure on the beating heart. Essentials of this hybrid therapy are a patch delivery device consisting of a polyester patch and a nitinol frame and a stapler system for fixation of the nitinol anchors. These elements have already been used by Vasilyev and colleagues ${ }^{17,18}$ for closure of atrial septal defects and mVSDs. In our hybrid therapy, the patch system was placed through the carotid artery into the LV and fixed with 8 to 10 nitinol anchors through LV puncture. Finally, the nitinol frame was detached from the patch. General feasibility of our technique was shown in a short-term porcine model. ${ }^{16}$ Until now, it was not known whether our new technique could close the mVSD sufficiently in the long term, nor was it known how cardiac function, especially LV function, would develop. We were also interested in the integration of the patch and the anchors into the muscular septum.

In this study, 2 of 12 pigs (17\%) died as a result of failure of the implantation technique. In the other animals $(88 \%)$, the mVSDs were successfully closed. Three of 12 animals $(25 \%)$ died of avoidable complications that were unrelated to the device.

We believe that this study supports the general feasibility of our technique. The 2 technical failures in our study were mainly related to problems with echocardiography and correct visualization and orientation. We believe upcoming improvements in imaging techniques, such as development of small tubes and holographic analysis, will lead to better results. Furthermore, training of the team is another important factor in the success rate. ${ }^{23}$

In 1 animal we detected 2 embolized anchors in the lung. For this reason, we modified our staplers with a 2-step release process to prevent the release of an anchor before it is inside the patch. After that modification, embolization of anchors was no longer observed.

We believe the LV approach to have some advantages relative to repair from the right ventricular side, such as better identification of the defect and better alignment of the patch because of the pressure gradient between the LV and the right ventricle. Until now, however, LV approaches have seldom been undertaken because of the risk of impaired LV function. ${ }^{6,24}$ In our hybrid therapy, only minimal LV 

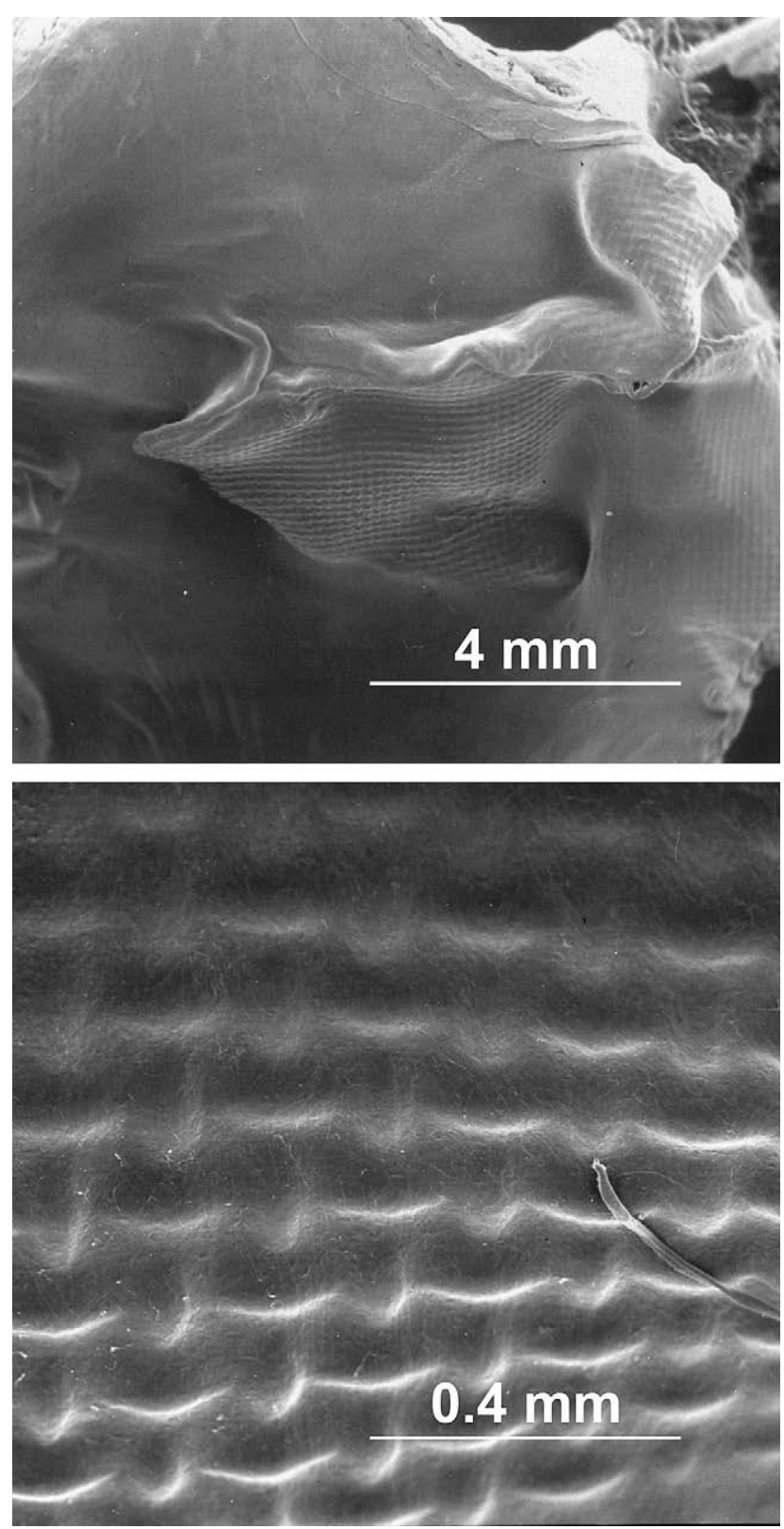

FIGURE 5. Characteristic scanning electron microscopy 3 months after implantation demonstrates patch to be covered by confluent monolayer of endothelial cells.

puncture, approximately $2 \mathrm{~mm}$ in diameter, is needed. This smaller puncture may be associated with a reduced risk of LV dysfunction. Our measurements of FS, also with dobutamine, after 1 and 3 months showed no reduction in cardiac function. In addition, an increase in PCWP could not be seen during follow-up, also indicating good LV function.

In our experiments, development of a slight elevation in PAP was seen; however, this was probably not due to a residual mVSD. The procedure itself was quite traumatic to the lungs in some experiments, especially because of the long operative times. We learned in the meantime that operative times could be significantly reduced with increasing experience. Two animals had pneumonia with elevated PAP, which must be also considered in the evaluation of PAP.

Postinterventional echocardiography showed mild insufficiency of the mitral, tricuspid, or aortic valve in some animals. Most insufficiencies of the atrioventricular valves decreased or vanished during the follow-up period. Structural damage to the valves was not seen. The insufficiency of the atrioventricular valves may have been due to the use of large sheaths. Consequently, techniques that do not need to pass the aortic valve would be preferable.

We performed histologic examinations on all explanted hearts, including those of animals that were killed early and those that completed the study through the follow-up period. In all hearts, macroscopic pathologic examination showed correct placement of the patch. In addition, adequate fixation of the patch could be detected, with no dislocation seen in any of the animals. Trivial residual shunting was noticed in just 1 animal during the follow-up period. These findings demonstrate that our technique was able to close the mVSDs sufficiently.

We performed investigations at different time points to demonstrate progressive coverage of the patch. Formation of a fibrin net with inclusion of blood cells on the surface of the polyester exposed to the blood could be detected by 3 days, followed by cells spreading over the fibrin net by 14 days. After 3 months, a confluent monolayer of cells, which could be identified as endothelial cells in immunohistochemical and SEM examinations, could be demonstrated in all specimens. Additionally, cellular organization proceeded in the first month after implantation with ingrowths of fibromuscular cells and the formation of loosely arranged vascular tissue. This is consistent with reports in the literature about the biocompatibility of cardiovascular implants, which described corresponding steps. ${ }^{25-27}$

The anchors were also completely overgrown by endothelium, indicating good integration of the patch into the muscular septum. Finally, superficial deposition of thrombotic material was not seen in any of the specimens.

A mild to moderate inflammatory reaction could be detected at the implantation site. Lymphocytic infiltration was found adjacent to the patch, indicating a persistent inflammatory reaction. Furthermore, foreign-body giant cells could be detected in our specimens and were considered to be part of the normal wound healing response. These reactions have also been described for various cardiovascular implants. ${ }^{25-27}$

\section{Study Limitations}

Our study was limited first because the defects were created iatrogenically, as opposed to being congenital defects. The procedure to create the defect was quite traumatic to the myocardium, as seen in the macroscopic and 
microscopic evaluation. This may have altered the healing and immune responses after patch implantation. Second, in terms of the long-term prospects for LV function, the implantation time of 3 months was short relative to the possible implantation time in human patients.

\section{CONCLUSIONS}

In conclusion, we demonstrated that with this new kind of hybrid approach mVSDs can be closed without patch dislocation through long-term follow-up. Global cardiac function was not reduced, and the patch was well integrated into the muscular septum. Finally, this study also confirmed satisfactory histologic findings for the polyester patch at different time points. Further improvement of the technique is necessary, however, before human use can be considered.

We thank Rabea Hinkel and Eckart Thein for critical comments on the manuscript.

\section{References}

1. Bacha EA, Hijazi ZM. Hybrid procedures in pediatric cardiac surgery. Semin Thorac Cardiovasc Surg Pediatr Card Surg Annu. 2005;78-85.

2. Hjortdal VE, Redington AN, de Leval MR, Tsang VT. Hybrid approaches to complex congenital cardiac surgery. Eur J Cardiothorac Surg. 2002;22:885-90.

3. Schmitz C, Esmailzadeh B, Herberg U, Lang N, Kozlik-Feldmann R, Sodian R, et al. Hybrid procedures can reduce the risk of congenital cardiovascular surgery. Eur J Cardiothorac Surg. 2008;34:718-25.

4. Kitagawa T, Durham LA 3rd, Mosca RS, Bove EL. Techniques and results in the management of multiple ventricular septal defects. J Thorac Cardiovasc Surg. 1998;115:848-56

5. Serraf A, Lacour-Gayet F, Bruniaux J, Ouaknine R, Losay J, Petit J, et al. Surgical management of isolated multiple ventricular septal defects. Logical approach in 130 cases. J Thorac Cardiovasc Surg. 1992;103:437-43.

6. Wollenek G, Wyse R, Sullivan I, Elliott M, de Leval M, Stark J. Closure of muscular ventricular septal defects through a left ventriculotomy. Eur J Cardiothorac Surg. 1996;10:595-8

7. Bellinger DC, Wypij D, Kuban KC, Rappaport LA, Hickey PR, Wernovsky G, et al. Developmental and neurological status of children at 4 years of age after heart surgery with hypothermic circulatory arrest or low-flow cardiopulmonary bypass. Circulation. 1999;100:526-32.

8. Zeitlhofer J, Asenbaum S, Spiss C, Wimmer A, Mayr N, Wolner E, et al. Central nervous system function after cardiopulmonary bypass. Eur Heart J. 1993;14: 885-90.

9. Madhok AB, Ojamaa K, Haridas V, Parnell VA, Pahwa S, Chowdhury D. Cytokine response in children undergoing surgery for congenital heart disease. Pediatr Cardiol. 2006;27:408-13.
10. Holzer R, Balzer D, Cao QL, Lock K, Hijazi ZM. Device closure of muscular ventricular septal defects using the Amplatzer muscular ventricular septal defect occluder: immediate and mid-term results of a U.S. registry. J Am Coll Cardiol. 2004;43:1257-63.

11. Thanopoulos BD, Rigby ML. Outcome of transcatheter closure of muscular ventricular septal defects with the Amplatzer ventricular septal defect occluder. Heart. 2005;91:513-6.

12. Diab KA, Cao QL, Mora BN, Hijazi ZM. Device closure of muscular ventricula septal defects in infants less than one year of age using the Amplatzer devices: feasibility and outcome. Catheter Cardiovasc Interv. 2007;70:90-7.

13. Garcia-Valentin A, Congiu S, Mayol J, Prada F, Mortera C, Pomar JL, et al. Device migration in hybrid technique for apical muscular ventricular septal defects closure. Interact Cardiovasc Thorac Surg. 2007;6:780-2.

14. Kozlik-Feldmann R, Lang N, Aumann R, Lehner A, Rassoulian D, Sodian R, et al. Patch closure of muscular ventricular septal defects with a new hybrid therapy in a pig model. J Am Coll Cardiol. 2008;51:1597-603.

15. Pavcnik D, Wright KC, Wallace S. Monodisk: device for percutaneous transcatheter closure of cardiac septal defects. Cardiovasc Intervent Radiol. 1993; 16:308-12.

16. Kozlik-Feldmann R, Lang N, Sodian R, Aumann R, Rassoulian D, Hinterseer M, et al. Creation of ventricular septal defects on the beating heart in a new pig model. Eur Surg Res. 2008;40:297-303.

17. Vasilyev NV, Martinez JF, Freudenthal FP, Suematsu Y, Marx GR, del Nido PJ Three-dimensional echo and videocardioscopy-guided atrial septal defect closure. Ann Thorac Surg. 2006;82:1322-6.

18. Vasilyev NV, Melnychenko I, Kitahori K, Freudenthal FP, Phillips A, Kozlik-Feldmann R, et al. Beating-heart patch closure of muscular ventricular septal defects under real-time three-dimensional echocardiographic guidance: a preclinical study. J Thorac Cardiovasc Surg. 2008;135:603-9.

19. Sigler M, Paul T, Grabitz RG. Biocompatibility screening in cardiovascular implants. Z Kardiol. 2005;94:383-91.

20. Quentin T, Poppe A, Bär K, Sigler A, Foth R, Michel-Behnke I, et al A novel method for processing resin-embedded specimens with metal implants for immunohistochemical labelling. Acta Histochem. Epub. 2008 Jun 11.

21. Okubo M, Benson LN, Nykanen D, Azakie A, Van Arsdell G, Coles J, et al. Outcomes of intraoperative device closure of muscular ventricular septal defects. Ann Thorac Surg. 2001;72:416-23.

22. Bacha EA, Cao QL, Starr JP, Waight D, Ebeid MR, Hijazi ZM. Perventricular device closure of muscular ventricular septal defects on the beating heart: technique and results. J Thorac Cardiovasc Surg. 2003;126:1718-23.

23. Bacha EA, Marshall AC, McElhinney DB, del Nido PJ. Expanding the hybrid concept in congenital heart surgery. Semin Thorac Cardiovasc Surg Pediat Card Surg Annu. 2007;146-50.

24. Griffiths SP, Turi GK, Ellis K, Krongrad E, Swift LH, Gersony WM, et al Muscular ventricular septal defects repaired with left ventriculotomy. Am J Cardiol. 1981;48:877-86.

25. Sigler M, Jux C. Biocompatibility of septal defect closure devices. Heart. 2007; 93:444-9.

26. Sigler M, Jux C, Ewert P. Histopathological workup of an Amplatzer atrial septal defect occluder after surgical removal. Pediatr Cardiol. 2006;27:775-6.

27. Sigler M, Kriebel T, Wilson N. Histological confirmation of complete endothelialisation of a surgically removed Amplatzer ASD occluder. Heart 2006;92:1723 